\title{
Silica templating of a self-assembling peptide amphiphile that forms nanotapes
}

Article

Published Version

Creative Commons: Attribution-Noncommercial 3.0

Open Access

Dehsorkhi, A. and Hamley, I. W. (2014) Silica templating of a self-assembling peptide amphiphile that forms nanotapes. Soft Matter, 2014 (10). pp. 1660-1664. ISSN 1744-683X doi: https://doi.org/10.1039/C3SM52324A Available at https://centaur.reading.ac.uk/36078/

It is advisable to refer to the publisher's version if you intend to cite from the work. See Guidance on citing.

To link to this article DOI: http://dx.doi.org/10.1039/C3SM52324A

Publisher: Royal Society of Chemistry

All outputs in CentAUR are protected by Intellectual Property Rights law, including copyright law. Copyright and IPR is retained by the creators or other copyright holders. Terms and conditions for use of this material are defined in the End User Agreement.

\section{www.reading.ac.uk/centaur}

\section{CentAUR}

Central Archive at the University of Reading

Reading's research outputs online 


\title{
Silica templating of a self-assembling peptide amphiphile that forms nanotapes $\dagger$
}

Cite this: Soft Matter, 2014, 10, 1660

\author{
Ashkan Dehsorkhi and lan W. Hamley*
}

Received 3rd September 2013

Accepted 29th January 2014

DOI: $10.1039 / \mathrm{c} 3 \mathrm{sm} 52324 a$

www.rsc.org/softmatter

The peptide amphiphile $\mathrm{C}_{16}$-KTTKS templates silica polymerization, enabling the production of silica nanotape structures, imaged via electron microscopy (TEM and SEM). X-ray scattering shows that the nanotapes comprise stacked layers, as for the parent peptide amphiphile, but with a substantially increased layer spacing resulting from silica polymerization.

\section{Introduction}

Biomineralisation is a natural biological process that occurs in order to harden tissue and as a result produces sophisticated and attractive inorganic structures..$^{1,2}$ Biomineralised structures in the human body includes bone and teeth, ${ }^{3}$ and in microorganisms examples include diatom cell walls ${ }^{4}$ and sea urchin spicules. ${ }^{5}$ The natural process of biomineralisation has inspired many to produce inorganic silica nanostructures by utilising the sol-gel reaction of silica. One method includes tetraethyl orthosilicate (TEOS), a silica precursor, which polymerises on the outer surface of organic templates. ${ }^{6,7}$ Applications of inorganic silica nanostructures have been used to provide versatile structural and functional materials in a wide range of areas such as electronics, catalysis, and sensors as well as biomedical applications such as drug delivery. ${ }^{8,9}$

Peptide amphiphiles (PA) have gained a huge amount of attention over the past decade due to their ability to selfassemble into a range of novel nanostructures. ${ }^{10,11}$ Their selfassembling abilities are dictated by their amphiphilic nature due to the inclusion of a lipid chain attached to a biofunctional peptide epitope that can participate in secondary structures such as $\beta$-sheets. ${ }^{12}$ The unique interplay of intermolecular hydrogen bonding along with hydrophobic and electrostatic interactions leads to well defined self-assembled nanostructures. $^{13,14}$ The ability to fine-tune these non-covalent

School of Chemistry, Pharmacy and Food Biosciences, University of Reading, Whiteknights, Reading, RG6 6AD, UK

$\dagger$ Electronic supplementary information (ESI) available. See DOI: $10.1039 / \mathrm{c} 3 \mathrm{sm} 52324 \mathrm{a}$ interactions provides flexibility in PA morphologies and therefore makes them ideal and attractive as organic templates to construct novel silica nanostructures.

Previous work using surfactant like peptides (SLP) as templates to fabricate silica hollow nanotubes has been reported. The Guler group reported the formation of silica nanofibres by using an amyloid-like peptide, Ac-KFFAAK-Am as a template to mimic the biomineralisation process. ${ }^{15}$ SLPs comprising $\mathrm{A}_{6} \mathrm{~K}$ and $\mathrm{V}_{6} \mathrm{~K}$ were studied by Wang et al. ${ }^{16} \mathrm{~A}_{6} \mathrm{~K}$ self-assembled into nanofibers whereas $\mathrm{V}_{6} \mathrm{~K}$ formed sheets with a lamellar stacking arrangement. Various anions were introduced to observe the influence on the morphology of the self-assembled nanostructures. Silica nanostructures were synthesised by the addition of silicic acid to solutions of peptide/anion mixtures. The formation of flower-like, fibrillar and lamellar morphologies was observed. The silica templating of a short SLP, $\mathrm{I}_{3} \mathrm{~K}$ from TEOS has been investigated by Zhang and co-workers. ${ }^{17}$ The amphiphilic peptide was reported to self-assemble into nanotubes and therefore the sol-gel condensation reaction of TEOS could be used to produce silica nanotubes. Their work also investigated the effects of TEOS concentration, $\mathrm{pH}$ and ageing on silica deposition. The Woolfson group conducted work on the silica templating of a designer peptide consisting of two $\alpha$-helical peptides, which co-assemble into a heterodimer. ${ }^{18}$ The resulting fibres were reported to be $50-100 \mathrm{~nm}$ wide. Long hollow silica nanotubes were formed by the silicic acid method. Investigation into the removal of the organic peptide core using a variety of methods was carried out which included enzyme degradation.

Previously the Hartgerink group investigated the templating effect of PAs using the sol-gel condensation of TEOS to synthesis hollow silica nanotubes. ${ }^{19}$ Five designer PAs were prepared to study the catalytic activities of amino acids on silica polymerisation. All five PAs self-assembled into $\beta$-sheet forming nanofibres. The PAs which contained lysine or histidine residues were reported to produce well-defined silica nanotubes due to the catalytic effects on their side chains. In this study we investigate the use of a collagen stimulating PA, $\mathrm{C}_{16}$-KTTKS as a 
template to construct nanotape silica structures using the solgel condensation reaction of TEOS. The self-assembly of $\mathrm{C}_{16^{-}}$ KTTKS has been well characterised by us previously. ${ }^{20-22}$ To our knowledge this is the first report on the production of flat tapelike silica nanostructures using a PA as the organic template.

\section{Experimental}

\section{Materials}

Peptide amphiphile $\mathrm{C}_{16}$-KTTKS, Palmitoyl-Lys-Thr-Thr-Lys-Ser, was purchased from CS Bio (Menlo Park, California) as a TFA salt. Purity was $99.15 \%$ by analytical HPLC, MS 802.05 (expected) 802.73 (measured).

\section{Sample preparation}

A solution of $1 \mathrm{wt} \% \mathrm{C}_{16}$-KTTKS was prepared by placing dry $\mathrm{C}_{16}$ KTTKS powder in a vial and adding ethanol to make up the defined concentration. This was followed by the addition of a $1 \mathrm{wt} \%$ solution TEOS in water. The mixture was sonicated for thirty minutes. The mixture was then stirred continuously for a week at room temperature to allow adequate time for TEOS polymerisation to occur.

\section{Calcination}

The one week aged solution was then placed in a rotavapour in order to evaporate the solvent leaving the silica coated nanostructures behind. The resulting solid was then calcined in a high-temperature oven at $350{ }^{\circ} \mathrm{C}$ for 10 minutes to remove all organic material (i.e. peptide amphiphile).

\section{Transmission electron microscopy (TEM)}

To prepare specimens for TEM, the calcined solid powder was dispersed in ethanol. Then droplets of the solution containing silica nanostructures were placed onto the TEM grid and was left to dry. The dried TEM grids were then negatively stained with uranyl acetate. TEM experiments were performed using a JEOL JEM-2010 microscope operated at $200 \mathrm{kV}$. Images were recorded using a Gatan Orius digital camera.

\section{Scanning electron microscopy (SEM)}

The calcined material was carefully deposited onto a conductive carbon adhesive disc, which was fixed to an aluminium stub. An FEI Quanta 600F SEM was used, which was operated in high vacuum mode at $25 \mathrm{kV}$.

\section{Cryogenic-transmission electron microscopy (cryo-TEM)}

Imaging was carried out using a field emission cryo-electron microscope (JEOL JEM-3200FSC), operating at $200 \mathrm{kV}$. Images were taken in bright field mode and using zero loss energy filtering (omega type) with a $20 \mathrm{eV}$ slit width. Micrographs were recorded using a Gatan Ultrascan 4000 CCD camera. The specimen temperature was maintained at $-187{ }^{\circ} \mathrm{C}$ during the imaging. Vitrified specimens were prepared using an automated FEI Vitrobot device using Quantifoil 3.5/1 holey carbon copper grids with $3.5 \mu \mathrm{m}$ holes. Just prior to use grids were plasma cleaned using a Gatan Solarus 9500 plasma cleaner and then transferred into an environmental chamber of a FEI Vitrobot at room temperature and $100 \%$ humidity. Thereafter 3 $\mathrm{ml}$ of sample solution ( $2 \mathrm{wt} \%$ concentration) was applied on the grid and it was blotted twice for 5 seconds and then vitrified in a $1 / 1$ mixture of liquid ethane and propane at temperature of $-180{ }^{\circ} \mathrm{C}$. The most viscous gel ( $5 \mathrm{wt} \%$ concentration) was blotted 4 times for $5 \mathrm{~s}$. The grids with vitrified sample solution were maintained at liquid nitrogen temperature and then cryotransferred to the microscope.

\section{X-ray diffraction (XRD)}

The calcined powder was placed onto Kapton tape and mounted (vertically) onto the four axis goniometer of a RAXIS IV++ X-ray diffractometer (Rigaku) equipped with a rotating anode generator. The sample-detector distance varied between 90 and $100 \mathrm{~mm}$ depending on the sample. The X-ray wavelength was $\lambda=1.54 \AA$. The wavenumber scale $(q=4 \pi \sin \theta / \lambda$ where $2 \theta$ is the scattering angle) was geometrically calculated using the size of each pixel in the detector screen $(0.0898 \mathrm{~mm})$ and the sampledetector distance. The XRD data was collected using a Saturn 992 CCD camera.

\section{Small-angle and wide-angle X-ray scattering}

SAXS data were collected on beamline ID02 at the ESRF, Grenoble, France. SAXS data were collected with a FReLoN Kodak CCD with a $1.2 \mathrm{~m}$ sample-detector distance. The X-ray wavelength was $0.995 \AA$ A. A solution containing 1 wt\% $\mathrm{C}_{16}$-KTTKS dissolved in ethanol mixed with $1 \mathrm{wt} \%$ TEOS was injected using a syringe into ENKI KI-beam thin $(0.05 \mathrm{~mm})$ wall $1.85 \mathrm{~mm}$ diameter poly-carbonate capillaries which optimize background subtraction. Measurements were performed at $25{ }^{\circ} \mathrm{C}$. All data were reduced to one-dimensional intensity profiles by radial integration.

SAXS data were also collected on the bioSAXS beamline BM29 at the ESRF, Grenoble, France. A solution of $1 \mathrm{wt} \% \mathrm{C}_{16}$ KTTKS was loaded into a PCR tube in an automated sample changer. SAXS data was collected using a Pilatus $1 \mathrm{M}$ detector. The sample-detector distance was $2.84 \mathrm{~m}$. The X-ray wavelength was $0.99 \AA$.

SAXS/WAXS for the calcined powder was performed using a Bruker Nanostar instrument using $\mathrm{CuK} \alpha$ radiation from an Incoatec microfocus source. The beam was collimated by a three slit system. The sample was mounted in a glass capillary (1 mm diameter). The sample-detector distance was $105 \mathrm{~cm}$ and a Vantec-2000 photon counting detector was used to collect SAXS patterns. The wavenumber $q=4 \pi \sin \theta / \lambda$ (where $2 \theta$ is the scattering angle and $\lambda=1.54 \AA$ is the wavelength) scale was calibrated using silver behenate. The powdered sample was placed on and wrapped with kapton tape which was then stuck onto a metal plate and placed in front of the beam.

\section{Results \& discussion}

The self-assembly of peptide amphiphile $\mathrm{C}_{16}$-KTTKS has been investigated by our group recently. ${ }^{20}$ We reported that the PA 
self-assembles into extended nanotape structures, based on stacked PA bilayers, above a critical aggregation concentration. ${ }^{21,22}$ We have selected a concentration of $1 \mathrm{wt} \% \mathrm{C}_{16}$-KTTKS to prepare silica nanotape structures, as it is well above the critical aggregation concentration $(0.03 \mathrm{wt} \%$ for the TFA salt in water $^{21}$ ). Silica mineralisation was carried out using a TEOS solution as the silica precursor mixed in a $1: 1$ solution with $\mathrm{C}_{16}$-KTTKS dissolved in ethanol, which was incubated at room temperature for one week followed by calcination.

The resulting silica templated structures of $\mathrm{C}_{16}$-KTTKS were examined by a combination of microscopy techniques. TEM images of the silica nanotape structures are shown in Fig. 1a and b. Flat sheet like structures were observed, which have strikingly similar structures to those of the PA $\mathrm{C}_{16}$-KTTKS itself. ${ }^{20}$ We also observed the presences of well-defined stripes running parallel to the surface of the silica nanotapes as presented in Fig. 1a. The stripe spacing from the TEM image was determined to be $4 \mathrm{~nm}$. Stripes have been noted previously for the PA itself. $^{23}$ The spacing is lower than the usual bilayer spacing $(5.2 \mathrm{~nm})$, and has been ascribed to the existence of a population of dehydrated bilayer structures. ${ }^{2425}$ The striped appearance is attributed to the nanostructures being viewed side-on. The previously reported $4 \mathrm{~nm}$ stripe spacing is in good agreement with that obtained from the TEM image in Fig. 1a for the calcined sample. A SEM image at high magnification of the calcined material shown in Fig. 1c reveals fibrillar structures as does the cryo-TEM image shown in ESI Fig. S1a. $\dagger$ An energydispersive X-ray spectrum was obtained via SEM shown in ESI Fig. $\mathrm{S} 2 \dagger$ for the calcined sample. The spectrum indicates that silica is present along with carbon and oxygen, which reveals that calcination was not fully completed. Nonetheless, calcination produced nanostructures with a predominant silica content.

To further elucidate the silica nanotape structure, SAXS was employed to complement the microscopy images. SAXS intensity profiles for $1 \mathrm{wt} \% \mathrm{C}_{16}$-KTTKS, precursor solution and calcined powder are shown in Fig. 2. The SAXS profile for a $1 \mathrm{wt} \%$ solution of $\mathrm{C}_{16}$-KTTKS dissolved in water contains peaks with positions in the ratio $1: 2$, which is indicative of layered structure due to the bilayer arrangement of the nanotape as observed previously. ${ }^{20} \mathrm{~A}$ solution containing $1 \mathrm{wt} \% \mathrm{C}_{16}$-KTTKS dissolved in ethanol was mixed with TEOS and left to age for a week for silica deposition. SAXS was measured for the precursor solution, which exhibits a peak with a $d$-spacing $=5.2 \mathrm{~nm}$, the same as that for $1 \mathrm{wt} \% \mathrm{C}_{16}{ }^{-}$ KTTKS in water. ${ }^{20,21,26}$ The second order lamellar reflection is not

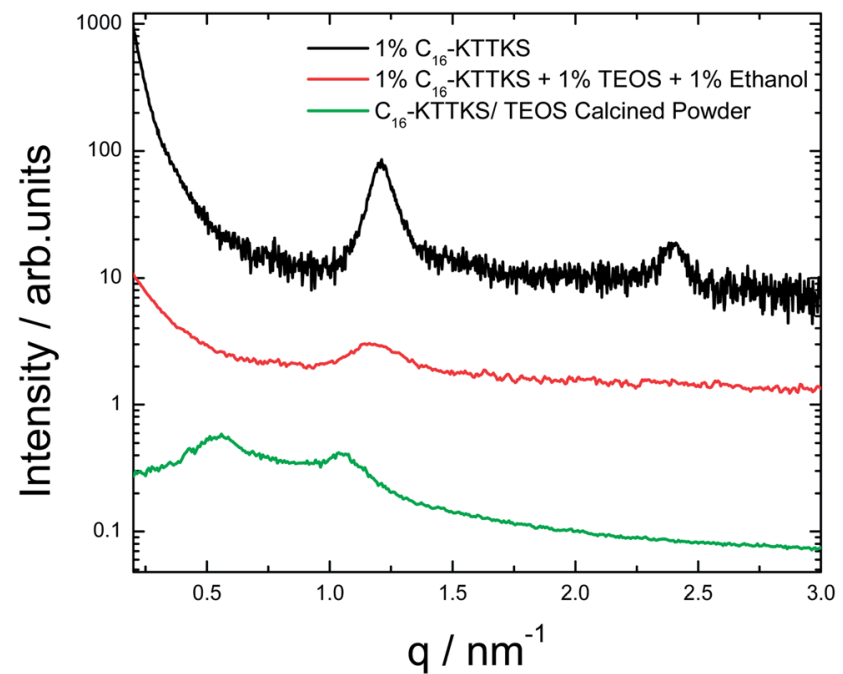

Fig. 2 SAXS data comparing 1 wt\% solution of $\mathrm{C}_{16^{-}}$KTTKS with $\mathrm{C}_{16^{-}}$ KTTKS precursor solution and calcinated powder.

present, indicating a reduction in long-range order. SAXS measurements for the calcined silica powder are also shown in Fig. 2, the profile contains Bragg reflections associated with a layered structure with a periodicity of $11.2 \mathrm{~nm}$. This indicates a substantial increase in the bilayer spacing, which we ascribe to swelling of the bilayers by silica upon drying. The precursor TEOS is believed to associate with the peptide headgroup due to electrostatic interactions, however there is no change in layer spacing for the precursor TEOS solution. The large increase in layer spacing for the calcined sample shows that silica templating does not occur via the direct liquid crystal templating route, ${ }^{27}$ but that it involves changes in the layer spacing due to silica polymerization upon calcination. Allowing the precursor solution to age for a week has been shown to provide sufficient time for silica polymerisation to occur.

$\mathrm{X}$-ray diffraction measurements were performed on calcined powders to observe any additional structural features in the wide angle region. A representative intensity profile is shown in Fig. 3. This shows a series of Bragg reflections which do not appear to be higher order peaks from the layered structure with 11.2 $\mathrm{nm}$ observed by SAXS. The absence of the meridional (4.7-4.8 $\AA$ ) $\beta$-sheet peak as previously observed ${ }^{20}$ indicates that $\beta$-sheet ordering is disrupted upon calcination. This is also supported by the near absence of the $11 \AA \beta$-sheet spacing
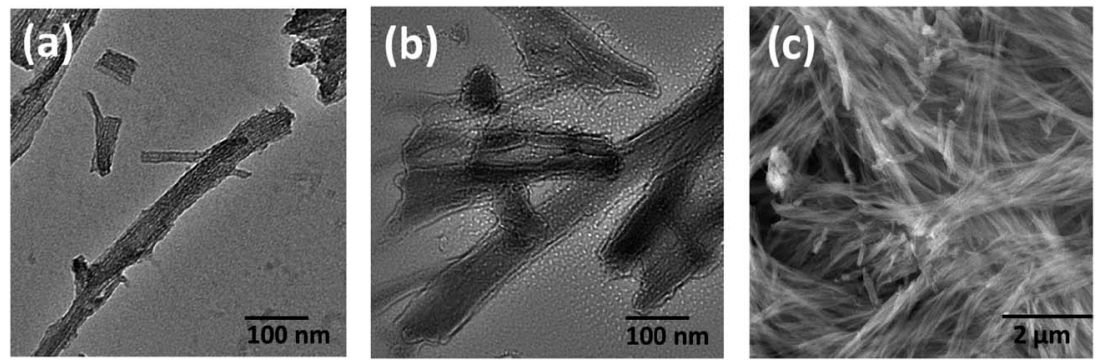

Fig. 1 (a and b) TEM images of the calcined $\mathrm{C}_{16}$-KTTKS-templated silica sample (c) SEM image of the silica nanostructure at high magnification. 


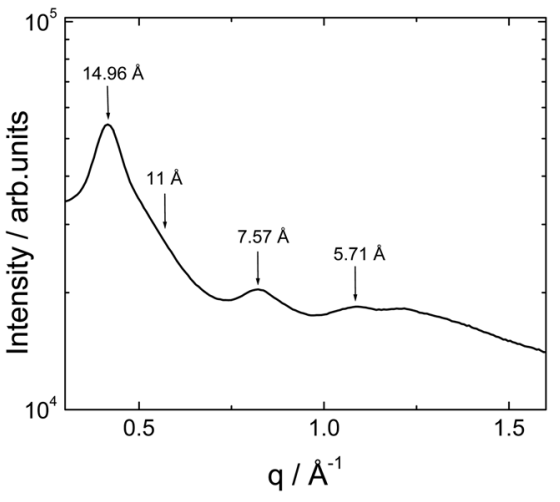

Fig. 3 WAXS data from the $\mathrm{C}_{16}$-KTTKS-templated silica nanostructure.

peak, ${ }^{23}$ which is only present as a weak shoulder. We ascribe the $14.96 \AA$ and $7.57 \AA$ reflections as second and third order peaks from a $3 \mathrm{~nm}$ periodicity dehydrated lamellar structure noted previously ${ }^{24}$ which may coexist with the TEOS-swollen $11.2 \mathrm{~nm}$ layer structure.

The primary amine group of lysine is known to exert a catalytic effect on TEOS hydrolysis. ${ }^{17,19,28}$ The PA we investigated, $\mathrm{C}_{16}$-KTTKS contains two basic lysine residues, which can catalyse the hydrolysis of TEOS. A mechanism for silica templating has been proposed by Hartgerink that the hydrolysed TEOS forms negative ions by deprotonation, which can in turn adhere to the positively charged primary amine group of lysine residues via electrostatic interactions. ${ }^{19}$ As $\mathrm{C}_{16}$-KTTKS selfassembles into a nanotape construct, the peptide epitope resides on the tape surface with the hydrophobic alkyl chains forming the core. We propose that silica deposition therefore occurs specifically on the surface of the nanotape structure, where the lysine residues are located.

As mentioned in the introduction, other authors have reported constructing silica nanotubes using amphiphilic peptides and PAs as templates but none have reported silica nanotapes. We report for the first time that a commercially available collagen stimulating PA, which can self-assemble into bilayers comprising a nanotape architecture can be templated using the sol-gel condensation reaction of TEOS to mimic silica biomineralisation.

In summary we have shown that flat sheet-like silica nanotapes with striations on some of the nanotape surfaces can be fabricated using a PA as a template. The silica nanotape stuructures were characterised using microscopy and scattering techniques, which reveal a similar structure as $\mathrm{C}_{16}$-KTTKS but with an increase in bilayer periodicity upon silica polymerization. XRD indicates that the inorganic polymerization overwhelms the initial $\beta$-sheet template features. Lysine residues present on the outer surface are believed to be responsible for catalysing the sol-gel condensation reaction of TEOS and subsequently template-directed synthesis of silica nanotapes.

\section{Acknowledgements}

This work was supported by EPSRC grant EP/G067538/1 to IWH. $\mathrm{X}$-ray diffraction experiments were performed in the BioCentre at the University of Reading. We thank Narayan Theyencheri (ESRF) for assistance with experiments on beamline ID02. Beamtime on beamline BM29 at the ESRF was awarded under reference MX-1401 and we thank Louiza Zerrad for support. We are grateful to Jani Seitsonen and Janne Ruokolainen for cryoTEM at Aalto University, Finland.

\section{References}

1 A.-W. Xu, Y. Ma and H. Calfen, J. Mater. Chem., 2007, 17, 415. 2 S. Mann, Biomineralisation: Principles and Concepts in Bioinorganic Materials Chemistry, Oxford, 2001.

3 C. Groger, K. Lutz and E. Brunner, Cell Biochem. Biophys., 2008, 50, 23-39.

4 C. W. Foo, J. Huang and D. L. Kaplan, Trends Biotechnol., 2004, 22, 577-585.

5 E. Beniash, J. Aizenberg, L. Addadi and S. Weiner, Proc. $R$. Soc. London, Ser. B, 1997, 264, 461-465.

6 Z. Cao, L. Dong, L. Li, Y. Shang, D. Qi, Q. Lv, G. Shan, U. Ziener and K. Landfester, Langmuir, 2012, 28, 7023-7032.

7 F. Hoffmann, M. Cornelius, J. Morell and M. Froba, Angew. Chem., Int. Ed. Engl., 2006, 45, 3216-3251.

8 Y. N. Xia, P. D. Yang, Y. G. Sun, Y. Y. Wu, B. Mayers, B. Gates, Y. D. Yin, F. Kim and Y. Q. Yan, Adv. Mater., 2003, 15, 353389.

9 M. Hartmann, Chem. Mater., 2005, 17, 4577-4593.

10 X. Zhao, F. Pan, H. Xu, M. Yaseen, H. Shan, C. A. Hauser, S. Zhang and J. R. Lu, Chem. Soc. Rev., 2010, 39, 3480-3498.

11 D. W. Löwik and J. C. M. v Hest, Chem. Soc. Rev., 2004, 33, 234-245.

12 I. W. Hamley, Soft Matter, 2011, 7, 4122.

13 S. E. Paramonov, H. W. Jun and J. D. Hartgerink, J. Am. Chem. Soc., 2006, 128, 7291-7298.

14 H. W. Jun, M. J. Webber and S. I. Stupp, Pept. Sci., 2009, 94, 1-18.

15 H. Acar, R. Garifullin and M. O. Guler, Langmuir, 2011, 27, 1079-1084.

16 Q. Wang, J. Yu, X. Zhang, D. Liu, J. Zheng, Y. Pan and Y. Lin, RSC Adv., 2013, 3, 2784.

17 S. Wang, X. Ge, J. Xue, H. Fan, L. Mu, Y. Li, H. Xu and J. R. Lu, Chem. Mater., 2011, 23, 2466-2474.

18 S. C. Holmstrom, P. J. S. King, M. G. Ryadnov, M. F. Butler, S. Mann and D. N. Woolfson, Langmuir, 2008, 24, 1177811783.

19 V. M. Yuwono and J. D. Hartgerink, Langmuir, 2007, 23, 5033-5038.

20 V. Castelletto, I. W. Hamley, J. Perez, L. Abezgauz and D. Danino, Chem. Commun., 2010, 46, 9185-9187.

21 J. F. Miravet, B. Escuder, M. D. Segarra-Maset, M. TenaSolsona, I. W. Hamley, A. Dehsorkhi and V. Castelletto, Soft Matter, 2013, 9, 3558.

22 V. Castelletto, I. W. Hamley, C. Whitehouse, P. J. Matts, R. Osborne and E. S. Baker, Langmuir, 2013, 29, 9149-9155.

23 V. Castelletto, I. W. Hamley, J. Adamcik, R. Mezzenga and J. Gummel, Soft Matter, 2012, 8, 217.

24 I. W. Hamley, A. Dehsorkhi and V. Castelletto, Langmuir, 2013, 29, 5050-5059. 
25 V. Castelletto, G. Cheng, C. Stain, C. J. Connon and I. W. Hamley, Langmuir, 2012, 28, 11599-11608.

26 A. Dehsorkhi, V. Castelletto, I. W. Hamley, J. Adamcik and R. Mezzenga, Soft Matter, 2013, 9, 6033.
27 G. S. Attard, J. C. Glyde and C. G. Göltner, Nature, 1995, 378, 366-368.

28 R. Ramanathan, J. L. Campbell, S. K. Soni, S. K. Bhargava and V. Bansal, PLoS One, 2011, 6, e17707. 